\title{
Experimental Validation of New Empirical Models of the Thermal Properties of Food Products for Safe Shipping
} Hanan H. Hamid * ${ }^{\text {a }}$, Mark Mitchell ${ }^{\text {, }}$ Amirreza Jahangiri ${ }^{\text {, }}$, David V. Thiel ${ }^{\text {a }}$

\author{
${ }^{\mathrm{a}}$ School of Engineering, Griffith University, Nathan 4111, Australia \\ buperCool Asia Pacific, Ormeau 4208, Australia \\ *Corresponding author. Address: School of Engineering, Griffith University, 170 Kessels \\ Road, Nathan Tel.: +61 737355574. \\ E-mail address: hanan.hamid@griffithuni.edu.au
}

\begin{abstract}
Temperature controlled food transport is essential for human safety and to minimise food waste. The thermal properties of food are important for determining the heat transfer during the transient stages of transportation (door opening during loading and unloading processes). For example, the temperature of most dairy products must be confined to a very narrow range $\left(3-7^{\circ} \mathrm{C}\right)$. If a predefined critical temperature is exceeded, the food is defined as spoiled and unfit for human consumption. An improved empirical model for the thermal conductivity and specific heat capacity of a wide range of food products was derived based on the food composition (moisture, fat, protein, carbohydrate and ash). The models that developed using linear regression analysis were compared with the published measured parameters in addition to previously published theoretical and empirical models. It was found that the maximum variation in the predicated thermal properties leads to less than $0.3^{\circ} \mathrm{C}$ temperature change. The correlation coefficient for these models was 0.96 . The t-Stat test $(\mathrm{P}$-value $>0.99)$ demonstrated that the model results are an improvement on previous works. The transient heat transfer based on the food composition and the temperature boundary conditions was found for a Camembert cheese (short cylindrical shape) using a multiple dimension finite difference method code. The result was verified using the heat transfer today (HTT) educational software which is based on finite volume method. The core temperature rises from the initial temperature $\left(2.7^{\circ} \mathrm{C}\right)$ to the maximum safe temperature in ambient air $\left(20.24^{\circ} \mathrm{C}\right)$ was predicted to within about $35.4 \pm 0.5$ minutes. The simulation results agree very well $\left(+0.2^{\circ} \mathrm{C}\right)$ with the measured temperature data. This improved model impacts on temperature estimation during loading and unloading the trucks and provides a clear direction for temperature control in all refrigerated transport applications.
\end{abstract}

Keywords: Thermal conductivity, Specific heat capacity, Food transport, Transient heat transfer, Empirical models, Finite difference method

\section{INTRODUCTION}

Food waste is a global problem; the food waste from the "field to the fork" is estimated to be 50\% [1]. In the USA alone, this equates to $\$ 165$ billion per a year loss when the food is not deemed safe for humans [2].

The thermal properties of food are required to evaluate the heat transferred from the surroundings to the food during the transient stages of shipping (loading and unloading). From this the time required to reach the critical temperature before the food becomes inappropriate for consumption and hence reduce the food waste percentage can be estimated.

The measured thermal properties (thermal conductivity, specific heat capacity, thermal diffusivity and density) data for many food groups can be found in many published documents [3-5]. In addition, many researchers present the thermal conductivity and specific heat capacity mathematically based on food composition (moisture, protein, fat, carbohydrate, ash and ice), thermal properties, mass and the volume [6, 7]. Other researchers built their empirical models for thermal conductivity and specific heat capacity based on the food material compositions to predict the thermal characteristics [3, 8]. There are few density empirical models, however this can be found mathematically as a function of the mass fraction and the density of each food component [7]. Different empirical thermal properties models were suggested by Marschount [9] although they were applied and tested for cheddar cheese only. The thermal diffusivity $(\alpha)$ of the food is more difficult to find as there is no significant relationship between it and the food compositions [9]. However, it is a function of the above three thermophysical parameters and can be found from the relationship [3]:

$$
\alpha=\frac{k}{\rho C_{p}}
$$

where $k$ is the thermal conductivity, $\rho$ is the density and $C_{p}$ is the specific heat capacity.

The prediction of the heat exchange and heat transfer of the food is very important; it helps to find the time temperature variation of the food at the transient temperature stages. A cooled container gains heat from the entered ambient air during the loading and unloading process when the doors at the loading dock are opened [10]. 
The amount of the transferred heat to the foods depends on the ambient temperature, the convection heat coefficient $(h)$ and the thermal parameters of the food which are based on the food composition. Different numerical methods were used to find the behaviour of the food under specific boundary conditions as the analytical models have very limited capabilities. The most common methods are the finite difference methods (FDM), the finite element method (FEM) and finite volume method (FVM) which can be used to estimate the thermal transfer for regular and irregular food shapes and for more complicated boundary conditions [11, 12].

The goals of this work were (1) to find an empirical model for thermal conductivity and specific heat capacity that can be applied for wide range of products and compare them with published results; (2) to find a calculation strategy which accurately predicts the required maximum time to load/unload the road vehicle before the critical temperature is reached by applying the estimated thermal properties in the FDM program to predict the heat transfer to the food; (3) to validate the simulated results with experiments for a camembert soft cheese product.

\section{TRANSIENT HEAT TRANSFER OF THE FOOD}

The transient heat conduction is a second order partial differential diffusion equation (Heat equation) which is solved to provide the temperature variation with the time and spatial coordinates [13]:

$$
\frac{\partial^{2} T}{\partial x^{2}}=\frac{1}{\alpha} \frac{\partial T}{\partial t}
$$

where $T$ is the temperature and $x$ is the distance. This equation can be used for any geometries and can be extended to deal with two and three dimensions. However, 1D and 2D analysis are usually sufficient to describe the heat transfer when one or two dimensions of the product are comparatively large. Equation (2) can be solved for the temperature distribution in the medium with defined temperatures at the boundaries (two temperature conditions for each coordinate direction).

The transient conduction for the two-multiple dimensional (cylindrical geometry) was found for the Camembert cheese using a one-dimensional explicit FDM solution. The heat transfer for a solid cylinder can be found from the product of the solution for infinite plane wall and cylinder.

When the door of a refrigerated trailer is opened, the heat is transferred to the food inside the trailer via the natural/free convection of the air currents. The natural convection heat transfer coefficient relies mainly on the ambient air properties and can be determined from:

$$
h=\frac{N u k}{L_{c h}}
$$

where $L_{c h}(\mathrm{~m})$ is the characteristic dimension, $k(\mathrm{~W} / \mathrm{m} . \mathrm{K})$ is the thermal conductivity of the medium and the $N u$ is the Nusselet number and it is function of Grashof number $(G r)$ and Prandtl number $(P r)$, the Nusselet number relation depends on many parameters such as the convection heat type (free natural or forced), the food dimension and shape (plate, cylinder, sphere, mushroomed etc..) and the flow direction to the sample [3].

The Nusselet equation for a free natural convection flow over a vertical cylinder is [14]:

$$
N u=\frac{4}{3}\left[\frac{7 G r P^{2}}{5(20+21 P r)}\right]^{1 / 4}+\frac{4(272+315 \operatorname{Pr}) L}{35(64+63 P r) D}
$$

where $L$ is the height and $D$ is the diameter of the cylinder. However, when the ratio $D / L \geq 35 \times G r^{-0.25}$ then the Nusselet equation for a vertical flat surface can be used for the vertical cylinder case [4]:

$$
\begin{aligned}
& N u=0.68+\frac{0.67 R a^{1 / 4}}{\left[1+(0.492 / P r)^{9 / 16}\right]^{4 / 9}} \\
& N u=\left\{0.825+\frac{0.387 R a^{1 / 6}}{\left[1+(0.492 / P r)^{9 / 16}\right]^{8 / 27}}\right\}^{2}
\end{aligned}
$$

where $R a$ is the Rayleigh number, it is the product of $G r$ and $P r$ numbers. Equation (5) can be applied when $10^{-1}<R a<10^{9}$ and Eq. (6) when $10^{9}<R a<10^{12}$.

\section{THERMAL PROPERTIES OF THE FOOD}

The experimental data of both thermal conductivity and specific heat capacity properties for different food groups (dairy products, fresh meat and chicken, and seafood) from the literature were compared to a theoretical model, a published empirical model and a suggested model to determine the best approximate value.

3.1 Thermal conductivity

The analytical model by Kopelman [6] was used where the predicted values depend mainly on the food structure. The formulation was different for homogeneous, isotropic and layered systems. Different theoretical models (series, parallel, Maxwell-Eucken and Kopelman isotropic) were tested. The best theoretical model was the parallel Kopelman model which is the same for Anisotropic and layered systems. The parallel thermal 
conductivity $(k||)$ of meat, fat layers on flesh and fibrous vegetables can be anticipated by this model [3, 5, 14, 15]:

$$
k \|=k_{L}\left[1-P\left(1-\frac{k_{s}}{k_{L}}\right)\right]
$$

where $P$ is the volume fraction of the solid/discontinuous phase and $k_{L}$ and $k_{s}$ are the thermal conductivities of liquid and solid phasers, respectively.

The same set of data was tested using the empirical model developed by Sweat [3]:

$$
k=0.58 X_{w}+0.16 X_{f}+0.155 X_{p r}+0.25 X_{c}+0.135 X_{a s h}
$$

where $X_{w}, X_{p r}, X_{f}, X_{a s h}$ and $X_{c}$ are the mass fraction of water, protein, fat, ash and carbohydrate, respectively. A linear regression method was used with multi-dimensional statistical analysis [16] and the empirical model that predicts the thermal conductivity based on the food composition was:

$$
k=0.6527 X_{w}+0.209 X_{f}+0.0988 X_{p r}+0.7145 X_{c}+1.6806 X_{a s h}-0.0582
$$

3.2 Specific heat capacity

The specific heat capacity in kJ/kg.K was predicted empirically using the multi-dimensional linear regression:

$$
C_{p}=6.099 X_{w}+3.97 X_{f}+4.22 X_{p r}+3.5 X_{c}+1.645 X_{a s h}-1.927
$$

The Choi and Okos [7] theoretical model was applied at the same temperature settings of the experimental measurement $\left(20^{\circ} \mathrm{C}\right)$ :

$$
C_{p}=\sum_{i=1}^{n} X_{i} C_{p i}
$$

where the $C_{p i}$ and $X_{i}$ are the specific heat and mass fraction of $i^{\text {th }}$ component, respectively and $n$ is the number of the food components.

The empirical model by Heldman and Singh [8] was also used for specific heat capacity predictions in (J/kg.K) for food according to five different compositions at $20^{\circ} \mathrm{C}$ :

$$
C_{p}=4187 X_{w}+1549 X_{p r}+1675 X_{f}+837 X_{a s h}+1424 X_{c}
$$

These statistical analyses were done to compare the predicted and the published models with the experimental data and to validate the suggested model. The statistical parameters used to determine the best models were: the correlation coefficient, the standard error of estimation (SEE) which measures the amount of error in the prediction of the model with respect to the measured values, the coefficient of determination $\left(R^{2}\right)$, the predictability (the mean of the difference between the experimental values and the modelled ones divide by the measured data) and the T-stat was calculated for each model as shown in Table I. The suggested empirical method shows the best performance among the other methods; both predicted models have a higher t-stat value of more than 0.99 which means the predicted results are very close to the measured ones and the absolute predictability is less than 0.01 . These models can be used to predict successfully the thermal conductivity and the specific heat capacity for the food products with moisture (15-90\%), protein (1-35\%), fat (0.01-83\%) and carbohydrate (0-54\%).

Figs 1 and 2 show the comparison of the specific heat capacity and the thermal conductivity for all of these methods with respect to the major food composition contributions (water, protein and fat). It is clear that the $k$ and $C_{p}$ values increase with the moisture mass fraction and decrease with the fat mass fraction.

\subsection{Density}

There are several density prediction models for each food material [3]. However, the Choi and Okos [7] is the most common model and can be applied for all food products and it is based on the food composition:

$$
\rho=\frac{1}{\sum_{i=1}^{n} X_{i} / \rho_{i}}
$$

where $\rho_{i}$ and $X_{i}$.are the density and mass fraction of $i^{\text {th }}$ food component.

\section{RESULTS AND DISCUSSIONS}

4.1 Camembert cheeses simulated parameters and results

The thermal conductivity and specific heat capacity of Camembert cheese sample were estimated using the suggested empirical models Eq. (9) and (10) while the density was calculated using Eq. (13) and the thermal diffusivity was calculated using Eq. (1). The mass composition fractions of the cheese provided by the manufacturer are shown in Table 2.

The change of the thermal properties on the sample core and surface temperatures was found at two different times of exposure using FDM numerical modelling. The simulation inputs assumed a two-dimensional finite cylinder. The parameters used in the simulation were the same in Table 2 and the $h_{\text {air }}$ value was $7.3 \mathrm{~W} / \mathrm{m}^{2} . \mathrm{K}$ 
( $h=7.3$ and 7.33 W/m².K using Eq.(4) and (5), respectively). The initial temperature was assumed to be $2.7^{\circ} \mathrm{C}$ and the ambient temperature was $20^{\circ} \mathrm{C}$. The simulation was run for 30 and 60 minutes following a step increase in ambient temperature. It was found that the maximum deviation of the estimated thermal conductivity value for many different kind of food using the suggested model was less than $0.03 \mathrm{~W} / \mathrm{m}$. K which causes less than $0.14^{\circ} \mathrm{C}$ and $0.1{ }^{\circ} \mathrm{C}$ temperature variations at the core and surface, respectively after 60 minutes.

The temperature at the core increases with the thermal conductivity parameter while the temperature at the surface was inversely proportional to the $k$ values (see Fig 3a). The variation in the estimated thermal conductivity of the cheese sample by $0.1 \mathrm{~W} / \mathrm{m} . \mathrm{K}$ leads to give different reading temperature. The variation in the temperature was the same at core and surface (about $0.5^{\circ} \mathrm{C}$ ) at both exposure times (30 and $60 \mathrm{~min}$ ). The temperature of the sample under test decreases with the density parameter. The temperature variation depends on the difference between the measured and the predicted density. If the difference between the measured density and that predicted was 200 $\mathrm{kg} / \mathrm{m}^{3}$, then the temperature variation was about $1^{\circ} \mathrm{C}$ at both the core and surface.

Eq. (13) was used to find the density of many food groups. If the food components are known, then the difference between the measured and modelled density was about $5-100 \mathrm{~kg} / \mathrm{m}^{3}\left(60 \mathrm{Kg} / \mathrm{m}^{3}\right.$ estimated density difference results in less than $0.3^{\circ} \mathrm{C}$ temperature variation after one hour of exposure to $20^{\circ} \mathrm{C}$ ambient) and $5.8 \%$ average absolute percentage error (percentage error $=100 \times$ (modelled-measured)/measured). If only two components are known (moisture and fat), the difference became higher up to $500 \mathrm{~kg} / \mathrm{m}^{3}$ (27.7\% average absolute percentage error) which leads to large temperature variations $\left(3.27^{\circ} \mathrm{C}\right.$ in the core and $2.46^{\circ} \mathrm{C}$ at the surface in 60 minutes) and results in a high prediction error.

The temperature decreased with the increasing of $C_{p}$. The maximum deviation from the measured values for more than $99 \%$ of data set was less than $200 \mathrm{~J} / \mathrm{kg} . \mathrm{K}$ which results in less than $0.3^{\circ} \mathrm{C}$ temperature variation at both core and surface of the sample after 30 and 60 minutes to exposure to the ambient temperature (see Fig 3c).

The natural convection coefficient from the surrounding air has the highest impact on the amount of the heat transferred to the food. A change in the ambient temperature and the air speed both directly affect the temperature (see Fig 3d).

The simulation was done for a 2D finite cylinder structure to represent the cheese sample. The temperature was mapped at two positions along the sample area: at the core (mid-plane) and on the surface (see Fig 4). The temperature increased rapidly in the first $30 \mathrm{~min}$ of the exposure (from $2.7^{\circ} \mathrm{C}$ to 6.7 and $11.39^{\circ} \mathrm{C}$ at core and surface, respectively) while in the next $30 \mathrm{~min}$ the temperature increase of the surface was slower than the core (by about $3^{\circ} \mathrm{C}$ for the surface and $4.4^{\circ} \mathrm{C}$ for the core). The simulation was repeated using the HTT software to certify the FDM results. The FDM simulation was very close to the HTT result with approximately $0.05^{\circ} \mathrm{C}$ tolerance at the core [17].

\subsection{Simulation and Experiment results}

Temperature measurements were undertaken at the NATA accredited facility at SuperCool Pty Ltd, Ormeau, South East Queensland. The facility is capable of logging up to 99 temperature sensors over periods of more than 24 hours with an accuracy of better than $0.01^{\circ} \mathrm{C}$. A cylindrical shaped camembert cheese was used as an example to compare calculated results with the experimental results. The transient heat transfer of a $125 \mathrm{~g}$ camembert cheese (code No. 6169580P) of $4.2 \mathrm{~cm}$ radius and $2.8 \mathrm{~cm}$ height was tested to mimic the temperature transfer and distribution scenario at the loading/unloading process in refrigerated transport.

The initial temperature of the cheese was $2.7^{\circ} \mathrm{C}$ and the temperature of the air was $20.24^{\circ} \mathrm{C}$. The camembert cheese was wrapped $(0.25 \mathrm{~mm}$ thickness waxed paper and $20 \mu \mathrm{m}$ polypropylene pasted to the wax paper), placed on $1.5 \mathrm{~cm}$ thickness plastic board which is set on 3mm stainless steel table and exposed to the ambient temperature. K-type wire thermocouples $(\mathrm{Ni} / \mathrm{Cr}-\mathrm{Ni} / \mathrm{Al})$ were used to measure the temperature on the surface and the core of cheese and the ambient temperatures with the time. The thermocouples were connected to a data acquisition system (5690, AHLBORN) to record the temperatures every 3sec. The simulation was done for 2D finite cylinder with thermal network scheme. The heat conductivities of wrapping layers as well as the plastic board and the stainless steel table were included in the simulation for the cheese and compared with the experimental results (see Fig 5). The overall heat transfer coefficient $(U)$ for the thermal network in Fig 6 was found from the lumped resistor model [18]:

$$
\begin{aligned}
& \frac{1}{U}=\frac{1}{h_{S E}}+\frac{1}{h_{\text {cond }}} \\
& \frac{1}{h_{S E}}=\frac{1}{h_{a}}+\frac{d_{W}}{k_{W}}+\frac{d_{p p}}{k_{p p}} \\
& h_{\text {cond }}=\frac{k_{S}}{d_{S}}+\frac{k_{p}}{d_{p}}
\end{aligned}
$$

where $h_{a}$ is the air heat convection, $h_{S E}$ is the equivalent heat convection coefficient results from three series thermal resistances ( $R_{\text {conv }}, R_{\text {cond,wrap } 1}$ and $\left.R_{\text {cond,wrap } 2}\right)$ and $h_{\text {cond }}$ is the equivalent heat convection coefficient produced by the two parallel thermal resistances ( $R_{\text {cond,plastic }}$ and $R_{\text {cond,steel }}$ ). The $d_{W}, d_{p p}, d_{p}$ and $d_{s}$ are the thickness of the 
waxed paper, polypropylene wrapping film, plastic board and stainless steel table, respectively. $K_{W}, k_{p p}, k_{p}$ and $k_{S}$ are the thermal conductivities of the waxed paper $(0.25 \mathrm{~W} / \mathrm{m} . \mathrm{K})$, PP film $(0.22 \mathrm{~W} / \mathrm{m} . \mathrm{K})$, plastic $\left(k_{p}=0.22 \mathrm{~W} / \mathrm{m} . \mathrm{K}\right)$ and stainless steel $\left(k_{S}=16 \mathrm{~W} / \mathrm{m} . \mathrm{K}\right)$, respectively.

Simulation of the Camembert cheese was undertaken using in-house the finite difference code based on equation (2). In order to match the experimental conditions, the core temperature of the cheese and the air temperature were fixed (Dirichlet boundary conditions) and the only air currents were convection currents.

Fig 5 shows that the simulated temperature response at the geometric centre of the cheese core of simulation with the thermal network was very close to the measured value at the first 40min of the simulation. The required times to reach the maximum safe shipping core temperature $\left(6.9^{\circ} \mathrm{C}\right)$ were 2122 and 2090 second for the experimental and simulation with the thermal network (wrapped cheese), respectively. However, in 2D simulation when the cheese was opened to the air (i.e. without the packaging) the time was less by $5 \mathrm{~min}$ as the wrapping reduces the transferred heat. The slopes for both experimental and thermal network simulation were very close 0.0021 and $0.0023 \mathrm{~min} /{ }^{\circ} \mathrm{C}$, respectively.

The surface temperature of the experimental result was higher than the simulated one at the beginning then the difference reduced gradually to be closer to the simulation result.

To validate the numerical simulation, the grid Fourier number was varied by changing the spatial step $(\Delta x)$ between $0.25 \mathrm{~mm}$ to $2.5 \mathrm{~mm}$. This results in a change in the time step of $0.78 \mathrm{sec}$ to $27 \mathrm{sec}$.

The root mean square error (RMSE) was calculated for each spatial step change for all data numbers $(n)$ to compare between the experimental $\left(T_{\exp }\right)$ and simulated temperatures $\left(T_{\text {sim }}\right)$ :

$$
R M S E=\sqrt{\sum_{i=1}^{n}\left(T_{\text {exp }}-T_{\text {sim }}\right)^{2} / n}
$$

For $\Delta x=2.5 \mathrm{~mm}$, the RMSE was $0.651^{\circ} \mathrm{C}$ at the core temperature calculation and $\Delta T=0.66^{\circ} \mathrm{C}$ at the maximum safe transportation temperature limit $\left(7^{\circ} \mathrm{C}\right)$ (see Fig 7$)$.

The American Cheese Society [19], recommended cheese storage temperature in the range 1.6-7.2 ${ }^{\circ} \mathrm{C}$ and for camembert cheeses. The bacteria start growing at $10^{\circ} \mathrm{C}$ [20]. From the simulated and experimental results, it is evident that the maximum exposure time to the ambient temperature should be less than 35min to maintain the cheese core temperature below $7^{\circ} \mathrm{C}$ at the cheese core. The slopes for the experimental result and the simulation based on the thermal network modelling were very close 0.0021 and $0.0023 \mathrm{sec} /{ }^{\circ} \mathrm{C}$, respectively.

\section{CONCLUSIONS}

Empirical models were developed to predict the thermal conductivity and the specific heat capacity of the different food groups. These models show high prediction accuracy, and when compared to the published theoretical and empirical models, the standard error of estimation was 0.02 and 0.1 for the thermal conductivity and specific heat capacity models, respectively. The t-Stat parameter was very high for both suggested models (Pvalue $>0.99$ ). These models were used to predict the thermal properties of the Camembert cheese. The FDM was used to simulate the heat transfer at the transient stage. 2D modelling was used to investigate the impact of the thermal properties and heat convection changes on the core and the surface of the cheese sample. It was found that no significant temperature variation (about $0.5{ }^{\circ} \mathrm{C}$ ) occurred when the thermal conductivity, specific heat capacity and density varied by $0.1 \mathrm{~W} / \mathrm{m} . \mathrm{K}, 200 \mathrm{~J} / \mathrm{kg} . \mathrm{K}$ and $100 \mathrm{~kg} / \mathrm{m}^{3}$, respectively. The major effect on the heat transfer resulted from changes in the heat convection coefficient.

The simulation results were compared with the HTT simulation and validated by experimental measurements to determine the temperature variations at the core and the surface of the cheese during the step change in ambient temperature. The scenario in the experiment corresponded well to the simulations after taking into consideration the impact of the cheese wrapping materials and the resting base of the cheese.

This simple analysis method provides transportation companies with all required thermal properties. The formulation accurately predicts the time that the food takes to reach a specific temperature as well as the maximum allowed time for loading/unloading process. While the technique has been applied to dairy products, it can be modified to suit all food products shipped at controlled temperatures. The model provides a very good match of the temperature profile with the experimental results. The next step in this work is producing a user-friendly interface window to examine the products response by entering the food compositions, initial and ambient temperatures and the time. The air humidity impact on the response will be considered in the future works.

\section{Acknowledgment}

The authors would like to thank Daniel Drennan, Ben Burgess and Jon Mitchell from the SuperCool Asia Pacific Pty Ltd for the help and providing the access to the test room to do the measurements. H. H. was supported by the Australian Government, Department of Industry and Science 03/07/2584 Research Connections. 


\section{Nomenclature}

$\mathrm{C}_{\mathrm{p}} \quad$ specific heat capacity, $\mathrm{J} \mathrm{Kg}^{-1} \mathrm{~K}^{-1}$

d thickness, $\mathrm{m}$

D diameter of the cylinder, $m$

Gr Grashof number (dimensionless)

$\mathrm{h} \quad$ convection heat transfer coefficient, $\mathrm{W} \mathrm{m}^{-2} \mathrm{~K}^{-1}$

$\mathrm{k} \quad$ thermal conductivity, $\mathrm{W} \mathrm{m}^{-1} \cdot \mathrm{K}^{-1}$

$\mathrm{k} \| \quad$ parallel thermal conductivity, $\mathrm{W} \mathrm{m}^{-1} \cdot \mathrm{K}^{-1}$

$\mathrm{L} \quad$ length, $\mathrm{m}$

$\mathrm{Nu} \quad$ Nusselet number (dimensionless)

Pr Prandtl number (dimensionless)

$\mathrm{R}$ thermal resistance, $\mathrm{KW}^{-1}$

$\mathrm{r}^{2} \quad$ correlation coefficient

$\mathrm{R}^{2} \quad$ coefficient of determination

$\mathrm{Ra} \quad$ Rayleigh number (dimensionless)

t time, sec

$\mathrm{T} \quad$ Temperature, $\mathrm{K}$

$\mathrm{U} \quad$ overall heat transfer coefficient, $\mathrm{W} \mathrm{m} \mathrm{m}^{-2} \mathrm{~K}^{-1}$

$\mathrm{x} \quad$ spatial distance, $\mathrm{m}$

$\mathrm{X} \quad$ mass fraction of the component

\section{Greek symbols}

a ambient

$\alpha \quad$ thermal diffusivity, $\mathrm{m}^{2} \cdot \mathrm{s}^{-1}$

$\beta \quad$ coefficient of thermal expansion, $\mathrm{k}^{-1}$

$\rho \quad$ density, $\mathrm{Kg} \mathrm{m}^{-3}$

\section{Subscripts}

$\begin{array}{ll}\text { a } & \text { ambient } \\ \text { ash } & \text { ash } \\ \text { c } & \text { carbohydrate } \\ \text { ch } & \text { characteristic length } \\ \text { conv } & \text { convection } \\ \text { cond,wrap } 1 & \text { conduction for warp1 } \\ \text { cond,wrap } 2 & \text { conduction for warp2 } \\ \text { cond,plastic conduction for plastic } \\ \text { cond,steel } & \text { conduction for stainless steel } \\ \text { f } & \text { fat } \\ \text { i } & \text { ith component } \\ \text { l } & \text { liquid } \\ \text { p } & \text { plastic } \\ \text { pp } & \text { polypropylene film } \\ \text { pr } & \text { protein } \\ \text { S } & \text { solid } \\ \text { S } & \text { stainless steel } \\ \text { SE } & \text { series components } \\ \text { w } & \text { moisture } \\ \text { W } & \text { waxed paper }\end{array}$




\section{References}

1. Smil, V. (2000) Feeding the World: A Challenge for the 21st Century, MIT Press Cambridge.

2. Gunders, D. (2012) Wasted: how America is losing up to 40 percent of its food from farm to fork to landfill. NRDC, Issue Paper, Natural Resources Defense Council. http://www.nrdc.org/food/wastedfood.asp, accessed on 20 Dec. 2016.

3. Rahman, M.S. (2009) Food properties handbook, CRC Press, $2^{\text {nd }} E d$.

4. ASHRAE (2009) Handbook fundamental (I-P) Ed, chapter 4, American Society of Heating, Refrigerating and Air-Conditioning Engineers Inc.

5. Berk, Z. (2009) Food process engineering and technology, Elsevier, 2nd Ed.

6. Kopelman, I.J. (1966) Transient heat transfer and thermal properties in food system, PhD thesis, Michigan State University.

7. Choi, Y., Okos, M.R. (1986) Effects of Temperature and Composition on the Thermal Properties of Foods. In Food Engineering and Process Applications, M. LeMaguer and P. Jelen, eds. Elsevier Applied Science, London 1, 93-101.

8. Heldman, D.R, Singh (1981) R.P., Food Process Engineering, 2nd Ed., Avi Pub. Co.

9. Marschoun, L.T, Muthukumarappan K., Gunasekaran S. (2006) Thermal properties of cheddar cheese: experimental and modelling. International Journal of Food Properties 4 (3), 383-403.

10. Vigneault, C., Thompson J., Wu S., Hui K.P , LeBlanc D.I. (2009) Transportation of fresh horticultural produce, Postharvest Technol. Hortic. Crops, 2, 1-24.

11. Wang, L., Sun, D. (2003) Recent developments in numerical modelling of heating and cooling processes in the food industry - a review. Trends in Food Science and Technology 14, 408-423.

12. Iezzi, R., Francolino, S., Mucchetti, G. (2011) Natural convective cooling of cheese: Predictive model and validation of heat exchange simulation. Journal of Food Engineering 106, 88-94.

13. Incropera, F.P., Dewitt, D.P., Bergman, T.L., Lavine, A.S. (2007) Fundamental of heat and mass transfer, John Wily and Sons, $6^{\text {th }}$ Ed.

14. Bejan, A., Kraus, A.D. (2003) Heat transfer handbook, Chapter 7, John Wiley \& Sons, Inc.

15. Sahin, S., Sumnu, S. (2006) Physical properties of foods, Springer Science.

16. Thiel, D.V. (2014) Research methods for engineers, Cambridge University Press.

17. University of Virginia, One-Dimensional Transient Conduction, http://www.faculty.virginia.edu/ribando/modules/OneDTransient/, accessed on 15 Dec. 2016.

18. Earle, R.L. (1983) Unit operations in food processing, chapter 5, Pergamon Press, 2nd Ed.

19. American Cheese Society, Tips on storage cheese, http://www.cheesesociety.org/i-heart-cheese/tipsfor-cheese-lovers/\#Storing, accessed on 16 Dec. 2016.

20. Fox, P.F., Guinee, T. P., Cogan, T. M., McSweeney, P.L. (2000) Fundamental of cheese science, Aspen Publishers, Inc.

21. ASHARE (2006) Handbook refrigeration (I-P) Ed, chapter 9, American Society of Heating, Refrigerating and Air-Conditioning Engineers, Inc. 

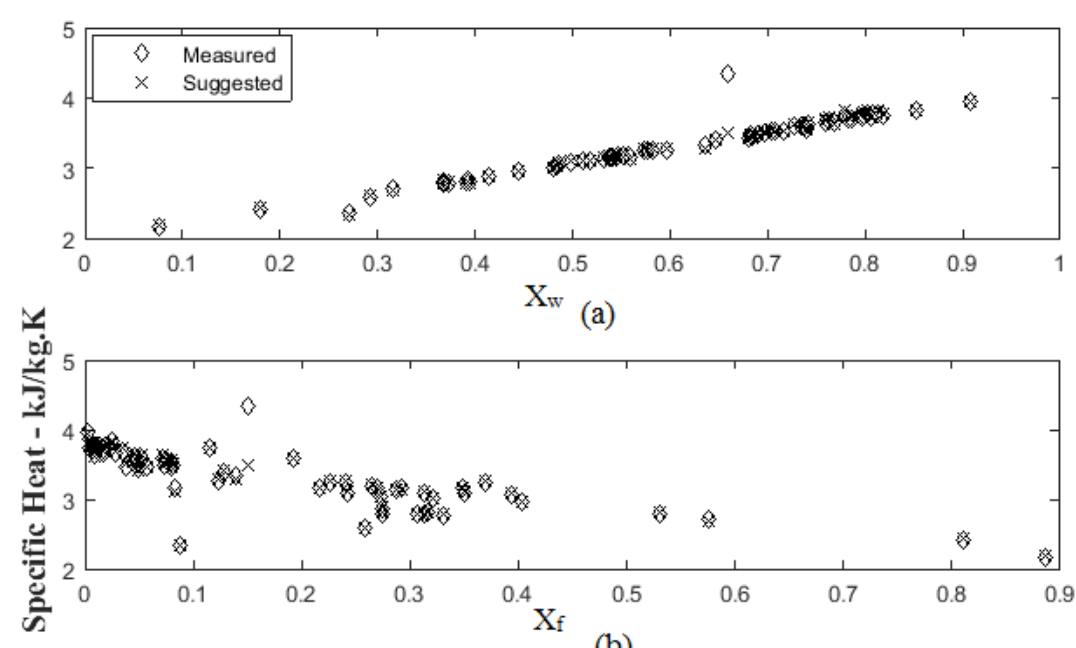

(b)

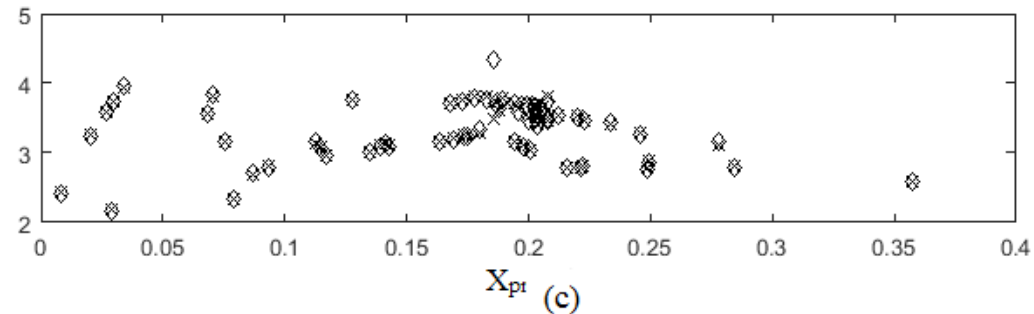

Fig 1 Comparison of the predicted specific heat capacity $\left(C_{p}\right)$ between the measured and predicted according to the food composition, (a) moisture, (b) fat and (c) protein. The measured values $(\diamond)$ are within the symbol size at most points of the points.

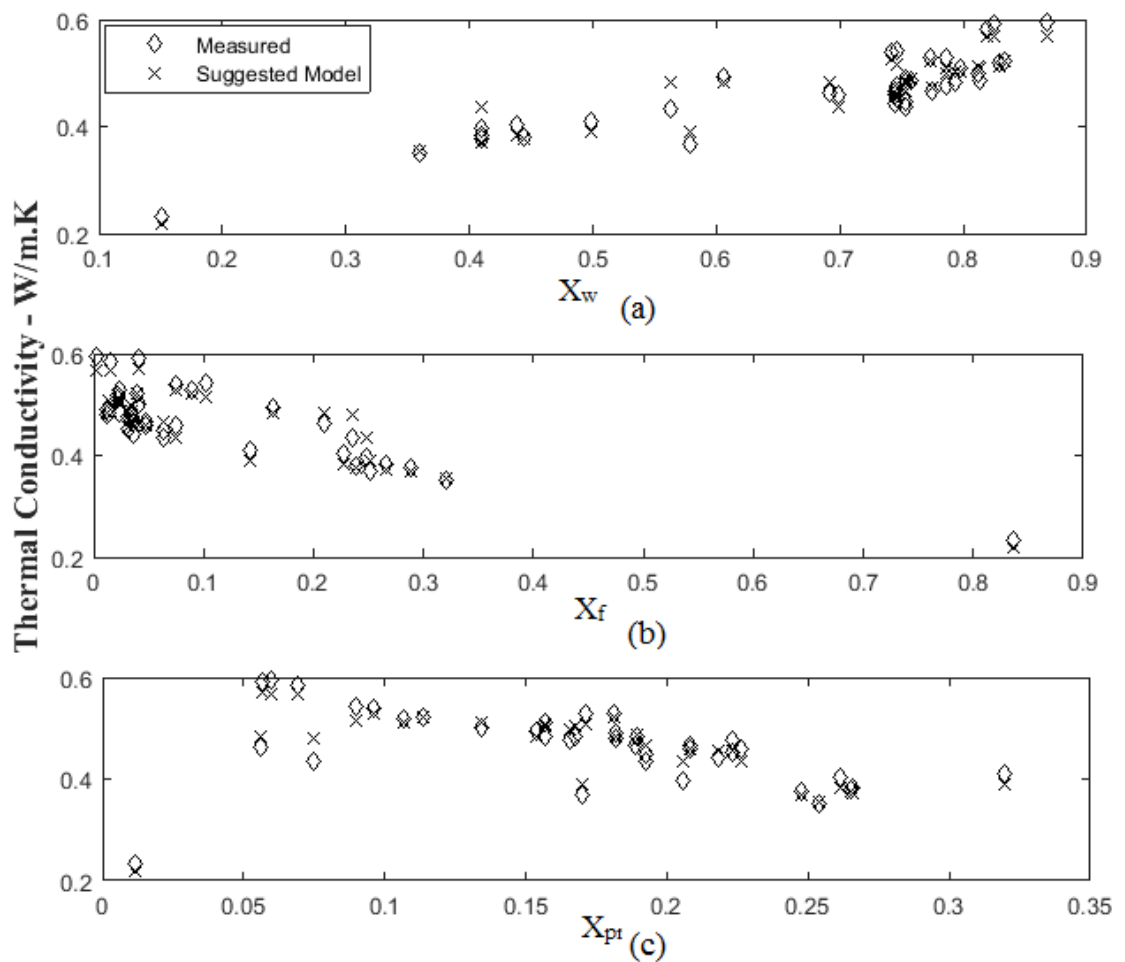

Fig 2 Comparison of the predicted thermal conductivity $(k)$ between the measured and predicted according to the food composition, (a) moisture, (b) fat and (c) protein. 


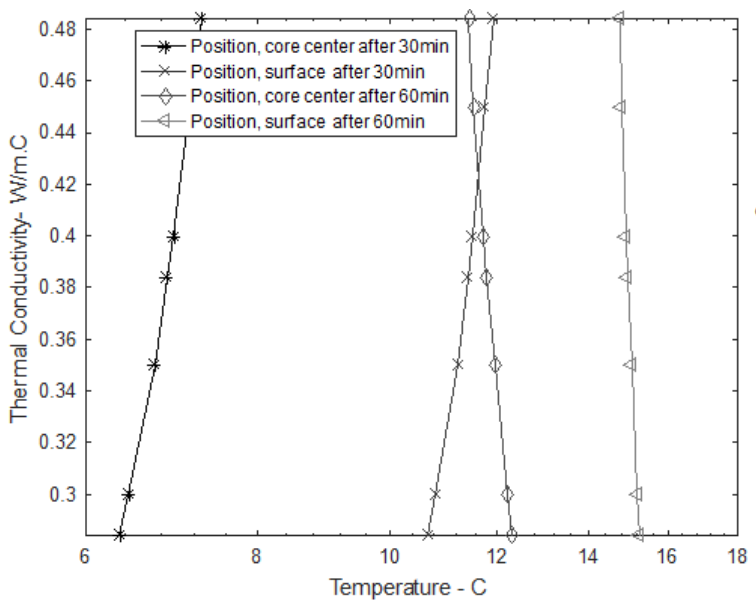

(a)

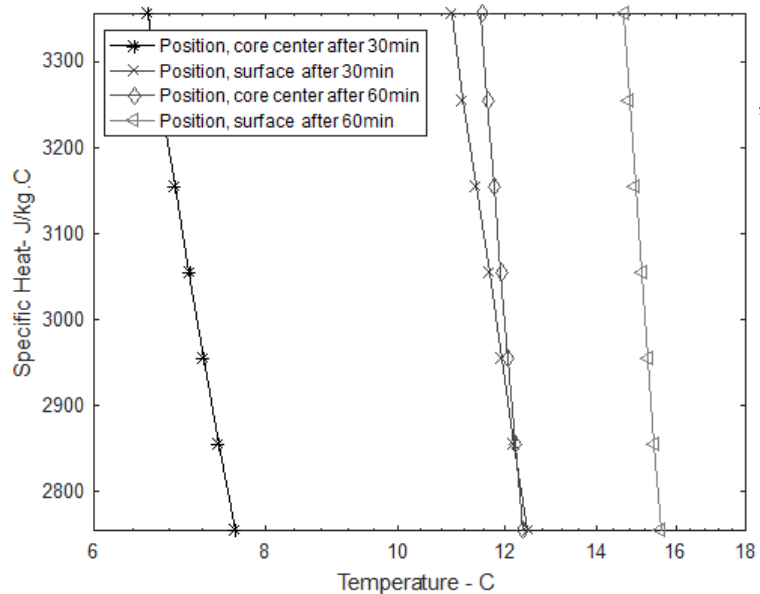

(c)

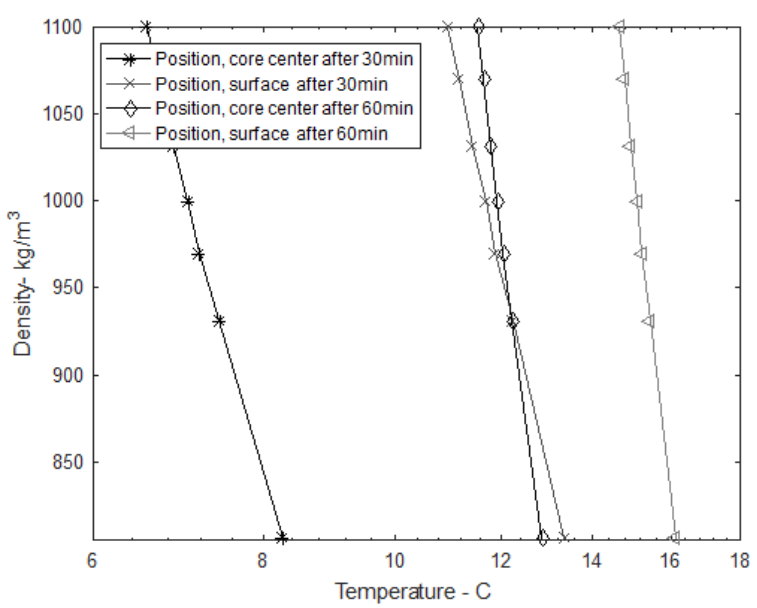

(b)

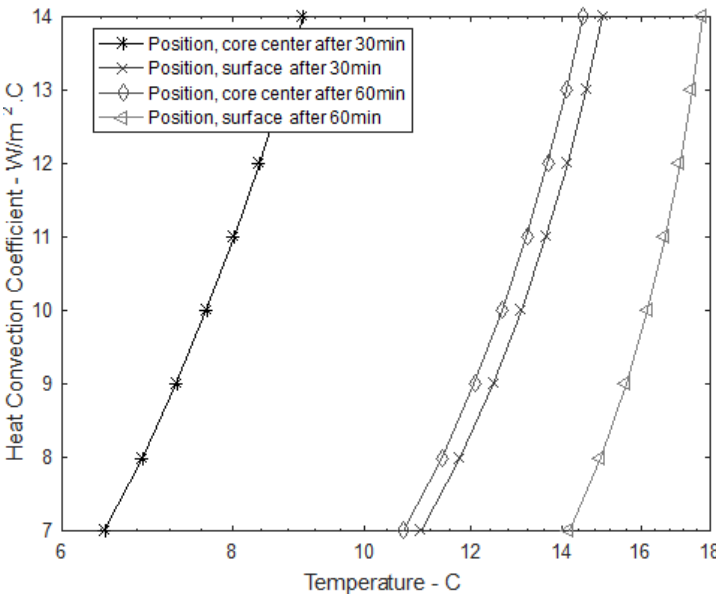

(d)

Fig 3 The impact of the uncertainty in the predicted thermal parameters on the calculated unwrapped cheese temperature at both the core and surface positions after 30 and 60 min exposure to the ambient temperature $\left(20^{\circ} \mathrm{C}\right)$ : (a): thermal conductivity, (b): density, (c): specific heat capacity and (d) heat convection coefficient. The hair value used for the first three plots was $8 \mathrm{~W} / \mathrm{m}^{2} . \mathrm{K}$. 


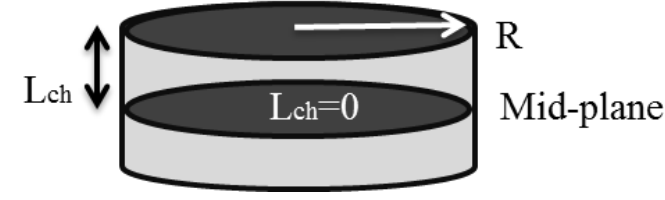

(a)

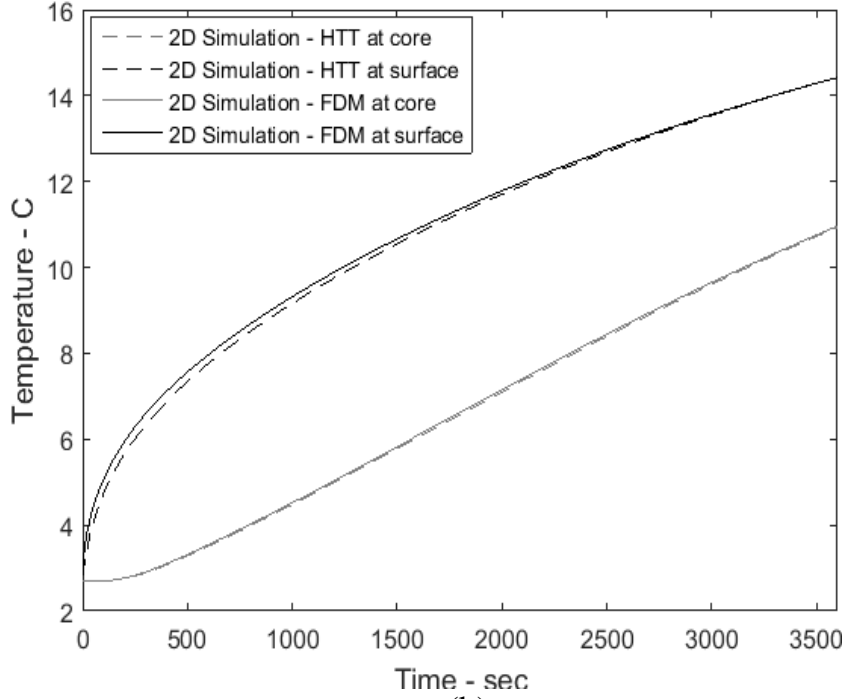

(b)

Fig 4 (a) Block diagram of the cheese sample shows the characteristic length (half-length $\left.L_{c h}\right)$ and the radius $(R)$ and (b) the temperature variation simulation at both core and surface in the cheese sample for 1 hour of $20^{\circ} \mathrm{C}$ of air temperature exposure using two different methods: FDM and HTT software. $R=0 \mathrm{~m}$ and $L_{c h}=0 \mathrm{~m}$ represents the core temperature and $R=0.042 \mathrm{~m}$ and $L_{c h}=0.014 \mathrm{~m}$ constitute the surface temperature.

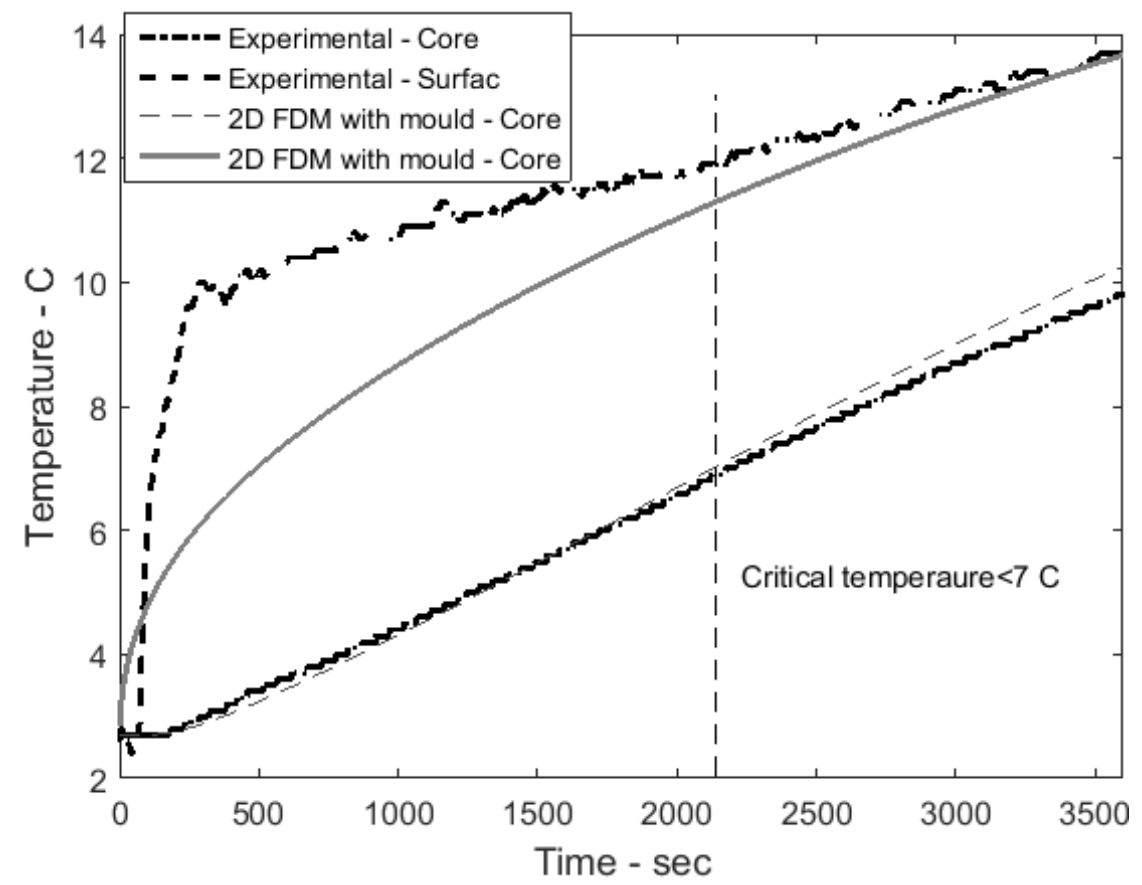

Fig 5 A comparison between the simulated (cheese opened to air and the wrapped cheese and placed on the plastic board and stainless steel table) and experimental transient heat transfer at the core and the surface of the camembert cheese. The initial temperature was $2.7^{\circ} \mathrm{C}$ and the average ambient temperature was $20.24^{\circ} \mathrm{C}$. Note the critical temperature for safe food transport is less than $7^{\circ} \mathrm{C}$. 


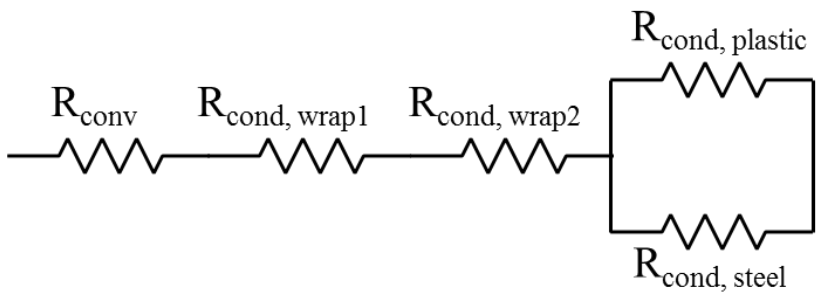

Fig 6 Thermal resistance network to model the wrapped Camembert cheese placed on two different layers (plastic and stainless steel).
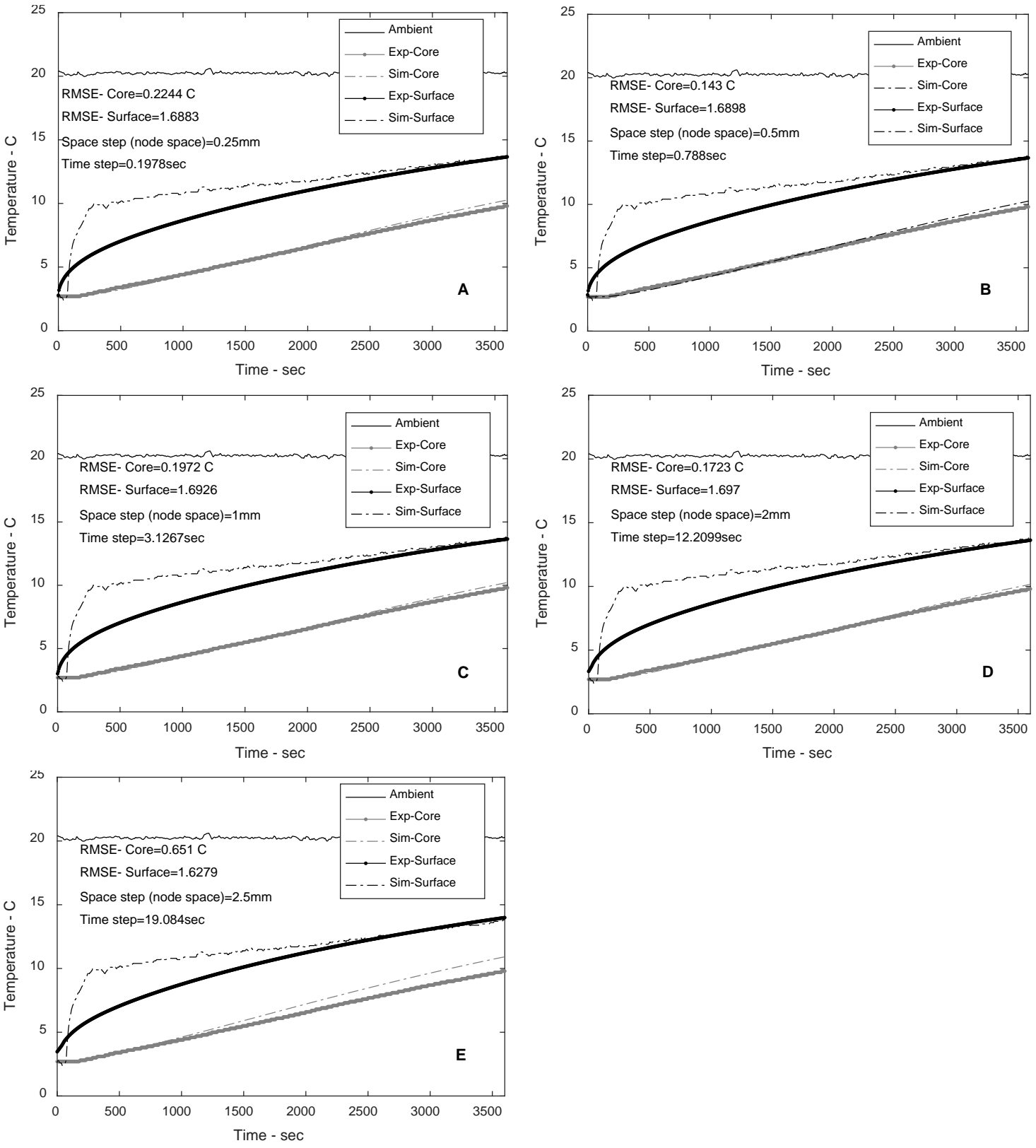

Fig 7 Comparison of tested and simulated core and surface temperatures of Camembert cheeses at different grid Fourier number by varying the spatial step $(\Delta x)$. 
Table 1

Statistical comparison among three models to predicate the thermal conductivity and specific heat capacity with respect to the experimental data from literatures.

\begin{tabular}{|c|c|c|c|c|c|c|}
\hline $\begin{array}{l}\text { Thermal } \\
\text { properties }\end{array}$ & Model & $\begin{array}{c}\text { Standard } \\
\text { error of } \\
\text { estimation } \\
\text { (SEE) }\end{array}$ & t-Stat & $\begin{array}{l}\text { Coefficient of } \\
\text { determination } \\
\qquad\left(R^{2}\right)\end{array}$ & $\begin{array}{c}\text { Correlation } \\
\text { coefficient } \\
\left(r^{2}\right)\end{array}$ & Predictability \\
\hline \multirow{3}{*}{$\begin{array}{c}\text { Thermal } \\
\text { conductivity }\end{array}$} & Kopelman at $20^{\circ} \mathrm{C}$ & 0.0364 & 0.2783 & 0.806 & 0.898 & -0.058 \\
\hline & Sweat & 0.033 & 0.2395 & 0.78 & 0.883 & 0.035 \\
\hline & Suggested & 0.0182 & 0.9987 & 0.931 & 0.965 & 0.008 \\
\hline \multirow{3}{*}{$\begin{array}{c}\text { Specific heat } \\
\text { capacity }\end{array}$} & $\begin{array}{l}\text { Choi and Okos at } \\
20^{\circ} \mathrm{C}\end{array}$ & 0.110 & 0.5559 & 0.93 & 0.964 & 0.006 \\
\hline & Heldman & 0.126 & 0.0416 & 0.927 & 0.963 & 0.043 \\
\hline & Suggested & 0.108 & 0.999 & 0.932 & 0.966 & -0.005 \\
\hline
\end{tabular}

Table 2

The thermal properties of a Camembert wrapped cheese with cylindrical shape (weight $125 \mathrm{~g}$, radius $0.042 \mathrm{~m}$ and $0.028 \mathrm{~m}$ height).

\begin{tabular}{ccccccccc}
\hline Moisture\% & Protein\% & Fat\% & Carbohydrate\% & Fibre\% & Ash\% & $\begin{array}{c}\text { Specific } \\
\text { Heat } \\
(\mathrm{J} / \mathrm{kg} . \mathrm{K})\end{array}$ & $\begin{array}{c}\text { Thermal } \\
\text { conductivity } \\
(\mathrm{W} / \mathrm{m} . \mathrm{K})\end{array}$ & $\begin{array}{c}\text { Density } \\
\left(\mathrm{kg} / \mathrm{m}^{3}\right)\end{array}$ \\
\hline 0.515 & 0.188 & 0.265 & 0.023 & - & 0.009 & 3140 & 0.368 & 1034.65 \\
\hline
\end{tabular}

